\title{
The peculiarities of professionalization of students-teachers with different levels of psychological stability
}

\author{
Evgeny Rogov', Ahmed Azhiev², Zarina Gadarbosheva², and Evgenia Rogova' \\ 'South Federal University, Academy of Psychology and pedagogics, 344006 Rostov-on- \\ Don, Russian Federation \\ ${ }^{2}$ Chechensky State Pedagogical University, Institute of pedagogics, psychology and \\ defectology, 364031 Grozny, Russian Federation
}

\begin{abstract}
The article is devoted to the study of the peculiarities of formation of professionalism of pedagogical high school students with different level of personal stability. The role of professional ideas as the characteristics of the professionalization of the subject is revealed. Quantitative and qualitative analysis of the peculiarities of development of a professional was carried out on the basis of the author's methods of assessing of professional ideas of students distributed in four groups, corresponding to the type of their professional orientation: "organizers", "subject teachers", "communicators" and "intellectuals". Analysis of the ideas about the object of future activity of students with different levels of stability demonstrated the existence of differences in the evaluation of the image parameters. It turned out that psychological stability is inversely interconnected with such parameters of ideas about the object as the activity and clarity. Indicators of ideas about the object of activity are also associated with the type of pedagogical orientation. The obtained data allow us to conclude that the personal stability of the subject in combination with the type of his professional orientation form an individual way of formation of the subject of pedagogical activity.
\end{abstract}

Professional development implies a certain stabilization, stability of the subject as the basis for further personal growth, the possibility of self-realization and the effectiveness of professional activity $[1 ; 2 ; 3$; etc.]. The psychological stability plays for professional a significant factor in efficient operation throughout the whole period of the initiative professional activity. At the same time the categorical apparatus of psychology does not contain an unambiguous interpretation of the concept of "psychological stability", often associated with successful adaptation to the environment or with the level of stability of the emotional sphere.

\footnotetext{
* Corresponding author: profrogov@yandex.ru
} 
The realities of modern society create an order for psychological science to analyze the anti-terroristic resistance [4]; anti-corruption stability [5]; anti-drug resistance [6]; information and psychological stability [7]; motivational and value stability [8]; neuropsychological stability [9]; health-preserving stability [10] and so on. However, even a significant number of works devoted to psychological stability, still does not allow to consider clarified the question of the role of stability in the professional development of the personality. Many researchers do not attribute stability to the category of individual qualities of a personality, but associate professional stability with the personality as a whole, analyzing it as a leading, monolithic characteristic or property of the subject $[11 ; 12$, etc.].

Considering mental stability as a successful opposition of the subject to extreme factors, its determinants include high intelligence, self-esteem, communicative competence, overcoming difficulties in development, effective social behavior, a variety of professional competencies and skills that ensure the achievement of goals in a particular professional activity [13].

Based on the principles of the activity approach V.V. Arshinova connected the category of psychological stability with self-regulation, defining it as the process of organization by a person of his behavior [6]. More complex forms of self-regulation of behavior and activity unfold at the final stages of the formation of professionalism determining by a welldeveloped consciousness [14]. The regularity of increasing of stability with age is determined by A. Kaspy, B.V. Roberts and R.L. Shiner as an "accumulative principle of continuous development of personality" [15].

The researches of B.V. Roberts and his colleagues showed that with age there is a growth and stabilization of such qualities as independence, self-confidence, goodwill and conscientiousness, while neuroticism decreases with the age [16]. According to other authors, this trend not only increases stability, quality and success at work, but also improves health, reduces the risk of mental disorders, and even reduce the probability of death $[16 ; 17 ; 18 ; 19$, etc. $]$. Among the factors of stabilization of personality and activity a separate role is given to fixed semantic settings [20].

An example of such setting affecting the behavioral stability can be the optimism (or pessimism) that is captured in the ideas of the subject about his achievements or failures. Martin Seligman [21] identified the following features of this assessment: firstly, the idea of constancy or changeability of successes and failures; secondly, the idea of their simultaneity or universality; thirdly, their attribution to one's own merits or success of others. A similar position is found in works of S. Maddy who defines stability as viability, as a kind of system that contributes to successful coping with various stressful situations. According to the author, the system is based on three components: involvement, control and risk taking [22; 23].

On the other hand, the lack of psychological stability at this stage can deform the process of professionalization, cause conflict actions, slow down the development of professional competencies.

The considered aspects of psychological stability emphasize their connection with the ideas that is especially important in the transition to the professional plane, requiring the disclosure of its role in the unstable period of formation of a professional, professional consciousness represented in professional images. In this case the research logic is based on the position that the formation of the subject's professionalism is accompanied by a change in the number and quality of his ideas about the profession [24]. In the course of the professionalization of the personality the ideas play a special role - figurative data about the professional environment become the main tool for the knowledge and foresight of a specialist. 
The analysis of the available works shows that there is an evident lack of researches aimed at studying of the process of formation of professionalism in persons with different degree of psychological stability by means of professional ideas, the scientific search for how the "figurative" basis manifests itself in the formation of a certain type of professional.

The empirical study was implemented on the basis of the Federal State Budgetary Educational Institution of High Professional Education "Chechen State Pedagogical University". The senior students of pedagogical specialties took part in the survey. The total number of respondents was 145 people. In the course of the study specific empirical methods that meet the developed target settings were used. Initially the level of stability of the respondents who were suggested to answer the questions of the test of viability of S. Maddi (adaptation of D.A. Leontiev and E.I. Rasskazova) was determined [25]. Then realizing the personality-oriented approach, the peculiarities of the professional orientation of future teachers were identified and their relevance to one of the professional types was determined using the method of assessing the professional orientation of the teacher's personality [26]. The study of the features of the professionalization process was based on the results obtained with the help of a questionnaire to assess the ideas about the object of activity [27]. The states arising in future teachers with different levels of stability were evaluated by the method of Ch.D. Spielberger [26] and the scale of subjective well-being of G. Perue-Badu [28].

According to the data of the method of assessing the psychological stability of S.Muddi, $14.5 \%$ of the respondents ( 21 persons) have a level of psychological stability below the average, which refers them to persons whose system of ideas about the world and about themselves does not always contribute to the effective overcoming of stressful situations. The majority of respondents - 73\% (106 persons) showed an average level of psychological stability and $12.5 \%$ (18 persons) - have a level above the average.

Then the respondents were offered a technique that evaluates their professional and pedagogical orientation. Types of professional orientation of the personality "Organizer" and "Intellectual" turned to be the most represented in the sample of future teachers: $30 \%$ (43 persons) and 27\% (39 persons) respectively. Type "Communicator" presents by 35 respondents (24\%) and type "Subject teacher" - 28 (19\%). The number of students with high stability is more represented in the types of "Organizer" (14\%) and " Subject teacher " (25\%), while the types of "Intellectual" and "Communicator" obviously differ in the prevalence of persons with low stability ( $23 \%$ and $20 \%$, respectively). Consideration of the representation of separate professional types at different levels of professional stability shows that from the total number of respondents with high stability $39 \%$ belong to the type of "Subject teachers" and 33\% - to the "Organizer". In the contingent with low stability $43 \%$ - are future teachers with the direction of "Intelligent" and 33\% - "Communicators".

The next stage of the study involves the diagnosis of the characteristics of the ideas of the subject about the object of his activity. At first the survey participants made a ranked list of three objects of their future professional activity. It turned out that regardless of the level of psychological stability the most popular object of future professional activity is the student. In the group with a high level of stability there is the largest number of versions of objects of activity.

The ideas about the object of activity in the group of respondents with a low level of psychological stability differ from students with high resistance to increased attention to such objects as academic discipline, parents of students and colleagues. This may be due to internal uncertainty and expectation of some threat. At the same time the processes of education and upbringing as objects of future activity cause them less concern and are not considered as a threat.

The respondents also evaluated the object of their activity on the proposed seven-point scale. As follows from the results, the different level of psychological stability is more 
reflected in such parameters of the ideas about the object as activity and clarity. At that the students with a low level of stability percept the object excessively active $(\mathrm{r}=-0.442, \mathrm{p} \leq$ $0.001)$, but less accurately and clearly $(\mathrm{r}=0.382, \mathrm{p} \leq 0.001)$, while , on the contrary, persons with a high level of stability do not consider it active $(r=-0.474, p \leq 0.001)$ and represent it well enough $(\mathrm{r}=0.514, \mathrm{p} \leq 0.001)$.

If we include in the consideration such aspect as the type of professional orientation of the teacher, we can note the highest assessment of the object given by representatives of the "Subject teacher" type, which indicates a positive attitude and acceptance of the object of activity. The students with a high level of stability and orientation "Intellectual" and "Organizer" give the highest points to the object by the parameter of strength, whereas representatives of the types "Communicator" and "Subject teacher " with a low level of stability refuse to represent the object as one possessing sufficient force.

Comparison of the results of the factor "Assessment" of the object by persons with different orientations demonstrates high values. Perhaps this is due to the adoption of professional community's norms and values by students in the process of receiving pedagogical education.

The factor "Strength" of the image is also highly represented among representatives of different types of professional orientation. The lowest rates are demonstrated by the students with low confidence and with a focus on the subject and communication, which may indicate their vision of the object of activity as not having sufficient self-control and due to external influences. Representatives of the "Organizer" and "Intellectual" types give higher points to this indicator forming the attitude to the object as to independent, selfconfident, counting only on himself in difficult circumstances.

A special attention is drawn to the data concerning the evaluation of the factor "Activity". Correlation analysis confirmed the existence of the inverse relationship on the principle of "the lower personal stability, the higher the estimated activity of the object." The same applies to persons with high stability, who, on the contrary, give low estimation to the activity of the object. In this case, the inverse dependence emphasizes the "invisibility" of the activity by the teachers with high personal stability in their object of activity.

The factor "Clarity" of the image of the object of activity did not find an expressed representation of future teachers. It is possible to note more exact, detailed representation of an image of object of professional activity in consciousness of "subject teachers" with high level of personal stability. The lack of clarity of the image of the object of activity of future teachers can serve as a harbinger of their orientation to the "object" approach in interaction with students, which does not involve taking into account the features and details of the object and is aimed primarily at finding "strong" means of influence on the object.

To assess the emotional state of students with different levels of psychological stability the average indicators of their anxiety level and the level of subjective well-being were compared. Respondents who have a high level of psychological stability differ from students with a low level of life-resistance and the level of personal anxiety (technique of Ch.D. Spielberger), the indicators of which revealed an inverse correlation $(\mathrm{r}=-0.491)$. Indicators of situational anxiety also have a correlation with psychological stability $(\mathrm{r}=$ 0.354). Therefore, it can be assumed that the presence of psychological stability supports the subject's positive emotional attitudes for the future, reducing anxiety, fear, raising interest in self-development, increasing optimism. At the same time the decrease in stability is manifested in the growth of unmotivated anxiety, an increase in alarming expectations.

Respondents with high psychological stability have a positive correlation with indicators of subjective well-being $(r=0.442)$, which indicates the prevalence of positive emotions, optimistic attitude to themselves and to others in this group of students. In the group with low psychological stability the connection with anxiety is statistically 
insignificant. This may indicate the probability of sudden appearance of anxiety, psychological distress, as indicators of lack of self-confidence when faced with various problems of self-realization, achievement of goals.

The analysis of differentiation of students' states depending on the type of pedagogical orientation and psychological stability showed that the lowest indicators of both personal and situational anxiety are demonstrated by representatives of all types of professional orientation with a high level of stability except the type of "Intelligent". The type "Intellectual" is characterized by a higher level of anxiety, which can be associated with the specifics of its focus on the transmission of spiritual values. At the same time there were no significant differences in the level of anxiety between respondents with high and low levels of stability.

The index of subjective well-being was significantly higher in representatives of all types of orientation with a high level of stability in comparison with persons with a low level of stability.

The conducted research allows us to approach the implementation of an individual approach in the training of teachers taking into account their personal stability, type of professional orientation, professional ideas and conditions that accompany this process.

The peculiarities of professionalization of students with high personal stability are associated with the choice as the objects of their activities: students, management and parents of students, highly evaluating their images on the factors of "Assessment" and "Strength" and low assessing the factor of "Activity". Formation is accompanied by positive emotional attitudes for the future, low anxiety, desire for self-development, optimistic attitude to yourself and to others, sufficient resources to meet difficulties. Professional ideas of students with high personal stability have their own specifics depending on the type of professional orientation of the future:

Type "Organizer": the ideas about the object are characterized by high indicators of assessment and strength factors at low activity factor. It is characterized by low personal anxiety and high level of subjective well-being.

Type "Intelligent": professional ideas have high indicators of the power and assessment factors at low factor of clarity.

Type "Communicator": professional ides are characterized by high rates of assessment factor at low activity factor. A low level of personal and situational anxiety is typical for it.

Type "Subject teacher": professional ideas demonstrate high indicators of assessment factor at low activity factor. It is characterized by low personal anxiety and a high level of subjective well-being.

The peculiarities of professionalization of students with low personal stability are determined by the objects of activity, which include students, academic discipline and parents of students. These images are highly evaluated by the factors of "Assessment" and "Activity", and lowly - by the factor of "Clarity". In the course of professionalization this group may experience a growth of unmotivated anxiety, an increase in anxious expectations and a lack of ability to stand up for their own interests when facing various problems in achieving of their goals. Professional ideas of students with low personal stability have their own specifics depending on the type of professional orientation of the future teacher:

Type "Organizer": the ideas about the object are characterized by high indicators of assessment and activity factors at low clarity factor. The level of subjective well-being is reduced which can be manifested in a lack of optimism and self-confidence.

Type "Intelligent": professional ideas have high indicators of the assessment factor at low factor of clarity. The formation of professionalism is accompanied by a high level of personal and situational anxiety, low level of subjective well-being.

Type "Communicator": professional ides are characterized by high rates of assessment and activity factors at low clarity factor. 
Type "Subject teacher": professional ideas have high indicators of assessment factor at low clarity factor. There is a high level of personal anxiety, low level of subjective wellbeing.

These characteristics can be implemented in the course of training and retraining of teachers.

\section{References}

1. O.S. Ovsyannikova, ANI: pedagogics and psychology. 16, 96-98 (2016)

2. S.N. Ochneva, T.S. Moroz, Akmeology. 49, 262 (2014)

3. K.A. Shinyaev, VAGU Gazette. 64, 200-206 (2013)

4. N.V. Buravtsova, SMALTA. 60, 12-16 (2015)

5. A.N. Pastushenya, MGUKI Gazette. 56, 25-28 (2013)

6. V.V. Arshinova, Psychological stability as a factor of formation of anti-drug attitude of adolescents (2007)

7. E.G. Baranov, TEPJournal. 10, 58-64 (2017)

8. A.V. Sazhin, Human capital. 57, 169-173 (2013)

9. N.V. Petrova, Actual problems of modern humanitarian science. 68-71, (2016)

10. K.I. Chizhova, SPO J. 6, 57-60 (2015)

11. S.S. Luthar, G. Cushin, Resilience and development: Positive life adaptations, 129-160 (1999)

12. P. Tempski, M.A. Martins, \& H.B. Paro, Medical education. 46, 345-346 (2012)

13. S.S. Luthar, D. Cicchetti, \& D. Becker, Child Development. 71, 543-562 (2000)

14. D. Kaprara, Psychology of a personality (2003)

15. A.Caspi, B.W.Roberts, \& R.L.Shiner, Annual Review of Psychology. 56, 453484 (2005)

16. B.W.Roberts, N.Kuncel, R.N.Shiner, A.Caspi, \& L.Goldberg, Perspectives in Psychological Science, 2, 313-345 (2007)

17. R.Kotov, W.Gamez, F.Schmidt, \& D.Watson, Psychological Bulletin. 136, 768-821 (2010)

18. J.D.Miller, \& D.Lynam, Criminology, 39, 765-798 (2001)

19. D.J.Ozer, \& V.Benet-Martínez, Annual Review of Psychology, 57, 401-421 (2006)

20. Z. Freid, I and it (2000)

21. E.P. Martin Seligman, Learned Optimism: How to Change Your Mind and Your Life (1991)

22. S.Maddi, Encyclopedia of Mental Health, Academic Press, 323-335 (1998)

23. D.Khoshaba, \& S.Maddy, Consulting Psychology Journal, 51, 106-117 (1999)

24. E.I. Rogov, The psychology of the formation of professionalism (2016)

25. D.A. Leontiev, E.I. Rasskazova, Test of viability (2006)

26. E.I. Rogov, Teacher as an object of psychological research (1998)

27. E.I. Rogov, SFU Gazette. Pedagogical sciences. 3, 145-162 (2008)

28. S.V. Duhnovsky, Diagnostics of interpersonal relations (2010) 